\title{
Intravaginally administered lactic acid bacteria expedited uterine involution and modulated hormonal profiles of transition dairy cows
}

\author{
Q. Deng, J. F. Odhiambo, U. Farooq, T. Lam, S. M. Dunn, M. G. Gänzle, and B. N. Ametaj ${ }^{1}$ \\ Department of Agricultural, Food and Nutritional Science, University of Alberta, Edmonton, Alberta, Canada T6G 2P5
}

\begin{abstract}
The objective of this investigation was to evaluate whether intravaginal infusion of lactic acid bacteria (LAB) around parturition could expedite involution rate of the uterus and improve reproductive performance of postpartum dairy cows. One hundred pregnant Holstein dairy cows were assigned to 1 of 3 experimental groups: (1) 1 dose of LAB in wk -2 and -1 and 1 dose of carrier in wk 1 relative to the expected day of parturition (TRT1); (2) 1 dose of LAB in wk $-2,-1$, and 1 (TRT2); and (3) 1 dose of carrier in wk $-2,-1$, and 1 (CTR). The LAB treatment was a lyophilized mixture of Lactobacillus sakei FUA3089, Pediococcus acidilactici FUA3138, and Pediococcus acidilactici FUA3140 with a cell count of $10^{8}$ to $10^{9} \mathrm{cfu} /$ dose. Uterine involution and ovarian activity was evaluated by transrectal ultrasonography weekly from d 7 to 49 postpartum. Blood samples were collected from a subset of cows to quantify prostaglandin (PG) $\mathrm{F}_{2 \alpha}$ metabolite (PGFM), $\mathrm{PGE}_{2}$, and progesterone. Cows treated with LAB had smaller cross-sectional areas of gravid horn and uterine body on d 14 postpartum. Cows in TRT2 resumed ovarian cyclicity earlier, as indicated by increased concentrations of serum progesterone. Cows in TRT1 had fewer days open than those in the CTR (110 vs. $150 \mathrm{~d}$ ), whereas cows in TRT2 and CTR did not differ in days open. In addition, both TRT1 and TRT2 increased the concentrations of PGFM at calving week, and cows in TRT2 also had greater concentrations of $\mathrm{PGE}_{2}$ on d 14 and $\mathrm{d} 21$ postpartum relative to CTR. Overall, cows treated intravaginally with LAB had smaller gravid horn and uterine body on d 14 postpartum than those in the CTR group. Treatment with LAB also increased concentrations of serum PGFM $(3,533 \pm 328 \mathrm{pg} / \mathrm{mL}$ in TRT1, $4,470 \pm 372 \mathrm{pg} / \mathrm{mL}$ in TRT2, and 2,000 \pm 328 $\mathrm{pg} / \mathrm{mL}$ in CTR on d 0, respectively), with the TRT1 group having fewer cows that resumed ovarian cyclicity but fewer days open compared with both TRT2 and
\end{abstract}

Received July 2, 2014.

Accepted May 28, 2015.

${ }^{1}$ Corresponding author: burim.ametaj@ualberta.ca
CTR groups. More research is warranted to better understand the mechanism(s) by which intravaginal LAB expedited uterine involution and affected hormonal profiles.

Key words: dairy cow, lactic acid bacteria, uterine involution, reproductive hormone

\section{INTRODUCTION}

Uterine infections, which refer to bacterial infections of the uterus, are prevalent in postpartum dairy cows (Sheldon et al., 2006). Normally, during the uterine involution period, the immune system is activated to clear invading pathogens and most dairy cows self-resolve the infections within $3 \mathrm{wk}$ after parturition (Bekana et al., 1996; Bondurant, 1999; Sheldon et al., 2006).

Infection of the uterus impairs reproductive performance of dairy cows and many of them become subfertile or infertile and are, therefore, culled from the herd (Sheldon et al., 2009a). Although the precise mechanism(s) by which uterine infections influence reproductive performance are not very well understood, they are mostly related to delays in uterine involution, resumption of ovarian activity, and prolongation of the luteal phase once ovulation occurs (Huszenicza et al., 1999; Mateus et al., 2002; Sheldon et al., 2009a). Indeed, cows with uterine infections exhibit lower conception rate, require more services per conception, and have more days open (Kasimanickam et al., 2004; Sheldon et al., 2009a). According to recent statistics, the culling rate of dairy cows in Canadian dairy herds reached $41.7 \%$, with infertility being the most frequent reason for culling (CanWest DHI, 2013).

Although several intrauterine or intravenous antibiotics have been used to treat cows with uterine infections, concerns about drug residues in the milk and bacterial acquisition of antibiotic resistance have impeded their widespread use (Lewis, 1997; Galvão, 2011). The use of lactic acid bacteria (LAB) or probiotics has been studied as a potential treatment for vaginitis in women (Reid and Bruce, 2003; Barrons and Tassone, 2008; Homayouni et al., 2014).

Probiotics are live microorganisms that benefit the host in various aspects when administered in adequate 
amounts, including modifying microbial composition and improving immunity (Reid et al., 2003; Verdu and Collins, 2005; Borchers et al., 2009). Lactic acid bacteria, mainly lactobacilli, have been utilized to treat urogenital infections in humans (Reid and Bruce, 2003). A previous study conducted by our group reported that 6 doses around calving with a cocktail of $3 \mathrm{LAB}$ isolated from the vaginal tract of healthy cows lowered the incidence of purulent vaginal discharge and improved conception rates of multiparous cows (Ametaj et al., 2014). Based on these results, we hypothesized that reducing the number of treatments around calving from 6 times to 2 or 3 treatments might result in the same beneficial effects. Therefore, the objectives of this study were to test whether treatment of cows with 2 doses of LAB (once per week) during the $2 \mathrm{wk}$ before the expected day of calving or treatment with 2 doses of LAB before calving and 1 dose during the first week after calving could improve uterine involution and reproductive performance of postpartum dairy cows.

\section{MATERIALS AND METHODS}

\section{Animals and Experimental Design}

This experiment was conducted at the Dairy Research and Technology Centre (DRTC) at University of Alberta, Canada. All experimental procedures were approved by the University of Alberta Animal Care and Use Committee for Livestock, and cows were cared for in accordance with the guidelines of the Canadian Council on Animal Care (1993). One hundred healthy pregnant Holstein cows in this study were enrolled $3 \mathrm{wk}$ before the due date and sequentially assigned into 1 of 3 treatment groups by sequential stratified block design according to parity (primiparous or multiparous), BCS (thin, $<3 / 5$; or not thin, $\geq 3 / 5$ ), and milk production (305 d $\geq 9,000 \mathrm{~kg}$ or $<9,000 \mathrm{~kg})$. The treatment groups were as follows: (1) 1 dose of LAB in wk -2 and -1 and 1 dose of carrier (sterile skim milk) in wk 1 relative to the expected day of parturition (TRT1); (2) 1 dose of LAB in wk -2 and -1 and 1 (TRT2); and (3) 1 dose of carrier in wk $-2,-1$, and 1 (CTR). The LAB treatment dose was a lyophilized mixture of Lactobacillus sakei FUA3089, Pediococcus acidilactici FUA3138, and Pediococcus acidilactici FUA3140, with a cell count of $10^{8}$ to $10^{9} \mathrm{cfu} /$ dose. Both LAB and the carrier were stored at $-86^{\circ} \mathrm{C}$ in vials in the form of dry powder, and each vial was reconstituted with $1 \mathrm{~mL}$ of sterile $0.9 \%$ saline before administration. The LAB or carrier was infused into the vaginal tract gently by using individually wrapped sterile infusion tubes (Continental Plastic Corp., Delavan, WI) capped with a 5 -mL sterile syringe (Becton, Dickinson and Company, Franklin Lakes, NJ), and deposited at the cranial vagina. Aseptic procedures were maintained during LAB administration.

\section{Determination of Uterine Involution and Resumption of Ovarian Cyclicity}

Uterine involution was evaluated by transrectal ultrasonography by an individual with no knowledge (i.e., blinded) of the treatment group assignments. A Sonosite ultrasound (Sonosite Inc., Bothell, WA) fitted with a $7.5-\mathrm{MHz}$ probe was used to obtain images of the cervix, uterine body and horns, follicles, and corpora lutea on ovaries of all cows weekly beginning on $d 7$ after calving until d 49. However, the uterine body was too large in many cows to be imaged in one frame on $\mathrm{d}$ 7. Therefore, only data for d $14 \pm 1.26, \mathrm{~d} 21 \pm 1.26$, d $28 \pm 1.23, \mathrm{~d} 35 \pm 1.23, \mathrm{~d} 42 \pm 1.37$, and d $49 \pm 1.37$ postpartum were used to determine uterine involution.

The longest and shortest diameters of a cervical crosssection were measured immediately before the caudal end of the cervix, whereas that of the uterine body and the 2 horns were measured immediately caudal and cranial to the bifurcation, respectively. As the boundary between myometrium and perimetrium is not as distinguishable as that between endometrium and myometrium, 2 perpendicular diameters of the cross-section were measured across the lumen and endometrium to calculate the cross-sectional area (CSA) of the cervix, uterine body, as well as gravid and nongravid horns (Okano and Tomizuka, 1987; Melendez et al., 2004).

Ovarian structures were examined for presence and size of follicles and presence of corpora lutea by ultrasonography to determine the resumption of ovarian cyclicity. If a large follicle ( $\geq 10 \mathrm{~mm}$ in diameter) was followed by a corpus luteum on the same ovary in a 14-d period, or a corpus luteum followed by a large follicle, then resumption of ovarian cyclic activity was declared. This was further corroborated by progesterone measurements described below.

\section{Assessment of Reproductive Performance}

Insemination and pregnancy diagnosis data were analyzed for all the cows enrolled in this experiment. The reproductive management program at the DRTC used the Presynch + Ovsynch protocol (Ambrose et al., 2006) to time ovulation on all cows. Therefore, all eligible animals were first inseminated around $66 \mathrm{~d}$ after calving. The median was $69(66-136) \mathrm{d}$ in TRT 1 , $67(65-97) \mathrm{d}$ in TRT 2 , and $68(66-148) \mathrm{d}$ in the CTR group. Pregnancy was declared when the pregnancy check was positive at $60 \mathrm{~d}$ after the insemination. Both timed artificial insemination (TAI) and pregnancy 
check were conducted by the same experienced technician. However, the technician and management were blinded to the cow treatments during the entire period of the experiment. Reproductive performance was indicated by first-service conception rate, cumulative pregnancy rate (up to 5 services), pregnancy rate at 150 DIM, services per conception, and number of days open.

\section{Quantification of Hormones}

Blood samples were collected from the coccygeal vein into $10-\mathrm{mL}$ Vacutainer tubes without anticoagulant (BD Vacutainer Systems, Plymouth, UK), before feeding in the morning, weekly from $\mathrm{d}-14$ to $\mathrm{d} 49$. Blood samples were centrifuged at $2,090 \times g$ at $4^{\circ} \mathrm{C}$ for 20 min (Beckman Coulter, Pasadena, CA) and serum was stored in pyrogen-free tubes at $-20^{\circ} \mathrm{C}$ until analysis. A subset of serum samples from 10 cows in each group was used to quantify the concentrations of progesterone, 13,14-dihydro-15-keto-PGF P $_{2 \alpha}$ (PGFM; indicative of the concentration of $\left.\mathrm{PGF}_{2 \alpha}\right)$, and $\mathrm{PGE}_{2}$ with enzyme immunoassay (EIA) kits following the manufacturer's instructions.

Serum samples collected weekly from d -14 to 21 were used to measure the concentration of PGFM with 13,14-dihydro-15-keto Prostaglandin F2 $\alpha$ EIA kits (Cayman Chemical Co., Ann Arbor, MI). Samples were diluted 10-fold with EIA buffer and standards were freshly prepared in serial as instructed in the manufacturer's manual. The limit of detection for PGFM was $13 \mathrm{pg} / \mathrm{mL}$ and sensitivity was $120 \mathrm{pg} / \mathrm{mL}$. The quantification of $\mathrm{PGE}_{2}$ used the same samples and followed the same procedures as used for PGFM with Prostaglandin E2 EIA kits, monoclonal (Cayman Chemical Co.). The limit of detection for $\mathrm{PGE}_{2}$ was $15 \mathrm{pg} / \mathrm{mL}$ and sensitivity was $50 \mathrm{pg} / \mathrm{mL}$. Serum samples collected on d -14 , $0,14,21,35$, and 49 were used to quantify progesterone; samples were also diluted 10-fold with EIA buffer. The procedures were the same as for PGFM and $\mathrm{PGE}_{2}$ except that the plate was incubated for $90 \mathrm{~min}$ at room temperature, instead of $18 \mathrm{~h}$ at $4^{\circ} \mathrm{C}$, before the wash and used Progesterone EIA Kits (Cayman Chemical Co.). The limit of progesterone detection was $10 \mathrm{pg} /$ $\mathrm{mL}$ and sensitivity was $70 \mathrm{pg} / \mathrm{mL}$. All samples were run in duplicate. The inter- and intraassay coefficients of variation were $<10 \%$ for all 3 hormones.

\section{Statistical Analyses}

All data were analyzed by using SAS 9.2 software (SAS Institute Inc., Cary, NC). To prove our hypothesis, a power analysis was conducted to determine the optimal number of cows per each group. Based on the uterine infection incidence rate of $45 \%$ on our university dairy farm, we expected that the LAB treatment could reduce the incidence rate by $30 \%$ (we assumed that both treatments would have the same effect on the reduction of the incidence rate of uterine infections). A statistical test using PROC POWER of SAS with a nominal power of $85 \%$ at a 0.05 one-sided significant level required a sample size of 33 (33 cows in each group) to detect a treatment difference. One hundred cows were enrolled in this study. However, 2 cows were dropped from the statistical analyses for not going through the treatment period.

Continuous data, including CSA of the cervix, uterine body, and horns, as well as concentrations of serum hormones, were analyzed using a MIXED model with repeated measurements. For CSA, a full model incorporating uterine infections, parity, treatment, days relative to calving, as well as their interactions, was first tested. We found no significant effect for the 3-way interaction, the 2-way interaction between parity and group, or that between parity and day. Uterine infections (clinical metritis, clinical endometritis, and pyometra) did not show a significant effect and inclusion of uterine disease did not improve the statistical model. Therefore, the statistical model was $Y_{\mathrm{ijkl}}=\mu+\mathrm{T}_{\mathrm{i}}+\mathrm{D}_{\mathrm{j}}$ $+(\mathrm{TD})_{\mathrm{ij}}+\mathrm{P}_{\mathrm{k}}+\mathrm{e}_{\mathrm{ijk} \mathrm{l}}$, where $\mu=$ the overall population mean; $T_{i}=$ effect of treatment; $D_{j}=$ effect of days relative to calving; (TD $)_{\mathrm{ij}}=$ effect of the interaction between treatment and days relative to calving; $\mathrm{P}_{\mathrm{k}}=$ effect of parity; and $\mathrm{e}_{\mathrm{ijkl}}=$ residual error. The subset of serum samples were all from multiparous cows, so the statistical model used to analyze the concentrations of serum PGFM and $\mathrm{PGE}_{2}$ was $\mathrm{Y}_{\mathrm{ijk}}=\mu+\mathrm{T}_{\mathrm{i}}+\mathrm{D}_{\mathrm{j}}$ $+(\mathrm{TD})_{\mathrm{ij}}+\mathrm{e}_{\mathrm{ijk}}$. The covariance structure was modeled using first-order autoregressive for the repeated measurements over time. A post hoc test was conducted if the interaction between the treatment and days was significant.

Binary data were analyzed using LOGISTIC procedure. The model for resumption of the ovarian cyclicity incorporated uterine infections, parity, treatment, and days relative to calving. Uterine infections did not show a significant effect and inclusion of uterine infections did not improve the statistical model. Therefore, they are excluded from the final model. Because no cows resumed cyclicity by d 14, results are presented only for d 21, 28, 35, 42, and 49 postpartum. The models for first-service conception rate, cumulative pregnancy rate, and pregnancy rate at 150 DIM incorporated parity and treatment. The interaction between parity and treatment was tested and we found that there was no effect on the dependent variables; therefore, it was 
excluded from the final model. Nonparametric data on services per conception and days open were analyzed using LIFETEST procedures. Wilcoxon test in the Kaplan-Meier model was used to test the effect of parity and group. For all data, significance was declared at $P<0.05$ and tendency at $0.05 \leq P<0.10$.

\section{RESULTS}

\section{Effect of Intravaginal LAB on Uterine Involution}

Of note, the data presented in this article are part of a large study with the main objective to lower the uterine infections of postpartum dairy cows, improve reproductive performance, and increase milk production that will be published in a series of manuscripts because of the large amount of data generated. However, some of the data on uterine infections and several other periparturient diseases are presented in Table 1 to assist in understanding the results. Cows treated with LAB (both TRT1 and TRT2) had lower incidence rates of metritis $(P<0.01)$ compared with those in the CTR group. We found no differences in terms of the incidence rates of clinical endometritis, pyometra, retained placenta, displaced abomasum, subclinical mastitis, or laminitis among the treatment groups.

The effect of LAB treatment on the CSA of the uterus is shown in Figure 1. We detected a tendency for an interaction between treatment and day $(P=0.08)$ for CSA of gravid horns (Figure 1A). On d 14 postpartum, the CSA of gravid horn in TRT1 and TRT2 were smaller than that in the CTR cows $(P<0.01)$ but did not differ between TRT1 and TRT2. Moreover, on d 21 postpartum, we detected a tendency for the CSA of gravid horn of cows in TRT1 to be smaller than that of cows in the CTR group $(P=0.08)$. The CSA in both TRT1 and TRT2 reached a plateau from d 21 through 49 postpartum, whereas in the CTR group,
CSA reached a plateau from d 28 through 49. In addition, multiparous cows had a larger gravid horn than primiparous cows $\left(3.50 \pm 0.10\right.$ vs. $2.94 \pm 0.20 \mathrm{~cm}^{2} ; P$ $<0.05)$.

The CSA of nongravid horns decreased over time until d 28 postpartum $(P<0.01)$, but no differences were detected among treatment groups and we detected no interaction between group and day in this study (Figure 1B). The CSA of nongravid horn was $2.65 \pm 0.07 \mathrm{~cm}^{2}$ and $2.11 \pm 0.13 \mathrm{~cm}^{2}$ in multiparous and primiparous cows, respectively $(P<0.05)$.

We detected a tendency for a significant interaction between treatment and day regarding the CSA of the uterine body $(P=0.08$; Figure $1 \mathrm{C})$. On d 14 postpartum, the CSA of the uterine body of cows was smaller in TRT1, intermediate in TRT2, and larger in CTR $(P$ $<0.05)$. The CSA of the uterine body in TRT2 reached a plateau from d 21, whereas that in both CTR and TRT1 tended to continue shrinking from d 21 to 28 postpartum. The CSA of uterine body was larger in multiparous cows than that in primiparous cows (5.22 \pm 0.17 vs. $\left.4.34 \pm 0.32 \mathrm{~cm}^{2} ; P<0.05\right)$.

The CSA of the cervix changed over time $(P<0.01)$ but not among the 3 treatment groups (Figure 1D). The CSA of the cervix decreased sharply from d 14 to 21 , followed by a plateau during the fourth week. Then, another decrease was observed from d 28 to 35 postpartum, after which a plateau was reached. No effect of the interaction between the treatment and day was observed on CSA of cervix. Parity did not affect the CSA of cervix.

\section{Effect of Intravaginal LAB on Resumption of Ovarian Cyclicity}

No interaction between treatment and day was detected regarding the resumption of ovarian cyclicity. The percentage of cows that resumed ovarian cyclicity

Table 1. Effect of lactic acid bacteria (LAB) on periparturient diseases of transition dairy cows

\begin{tabular}{|c|c|c|c|c|}
\hline \multirow[b]{2}{*}{ Disease, \% (case/total) } & \multicolumn{3}{|c|}{ Treatment $^{1}$} & \multirow[b]{2}{*}{$P$-value } \\
\hline & TRT1 & TRT2 & CTR & \\
\hline Metritis & $15(5 / 34)^{\mathrm{b}}$ & $6(2 / 32)^{b}$ & $38(12 / 32)^{\mathrm{a}}$ & 0.007 \\
\hline Clinical endometritis & $6(2 / 34)$ & $9(3 / 32)$ & $13(4 / 32)$ & 0.62 \\
\hline Pyometra & $3(1 / 34)$ & $6(2 / 32)$ & $3(1 / 32)$ & 0.84 \\
\hline Retained placenta & $3(1 / 34)$ & $6(2 / 32)$ & $13(4 / 32)$ & 0.29 \\
\hline Displaced abomasum & $0(0 / 34)$ & $0(0 / 32)$ & $6(2 / 32)$ & 0.33 \\
\hline Subclinical mastitis ${ }^{2}$ & $40(8 / 20)$ & $50(10 / 20)$ & $55(11 / 20)$ & 0.90 \\
\hline Laminitis & $9(3 / 34)$ & $9(3 / 32)$ & $6(2 / 32)$ & 1.00 \\
\hline
\end{tabular}



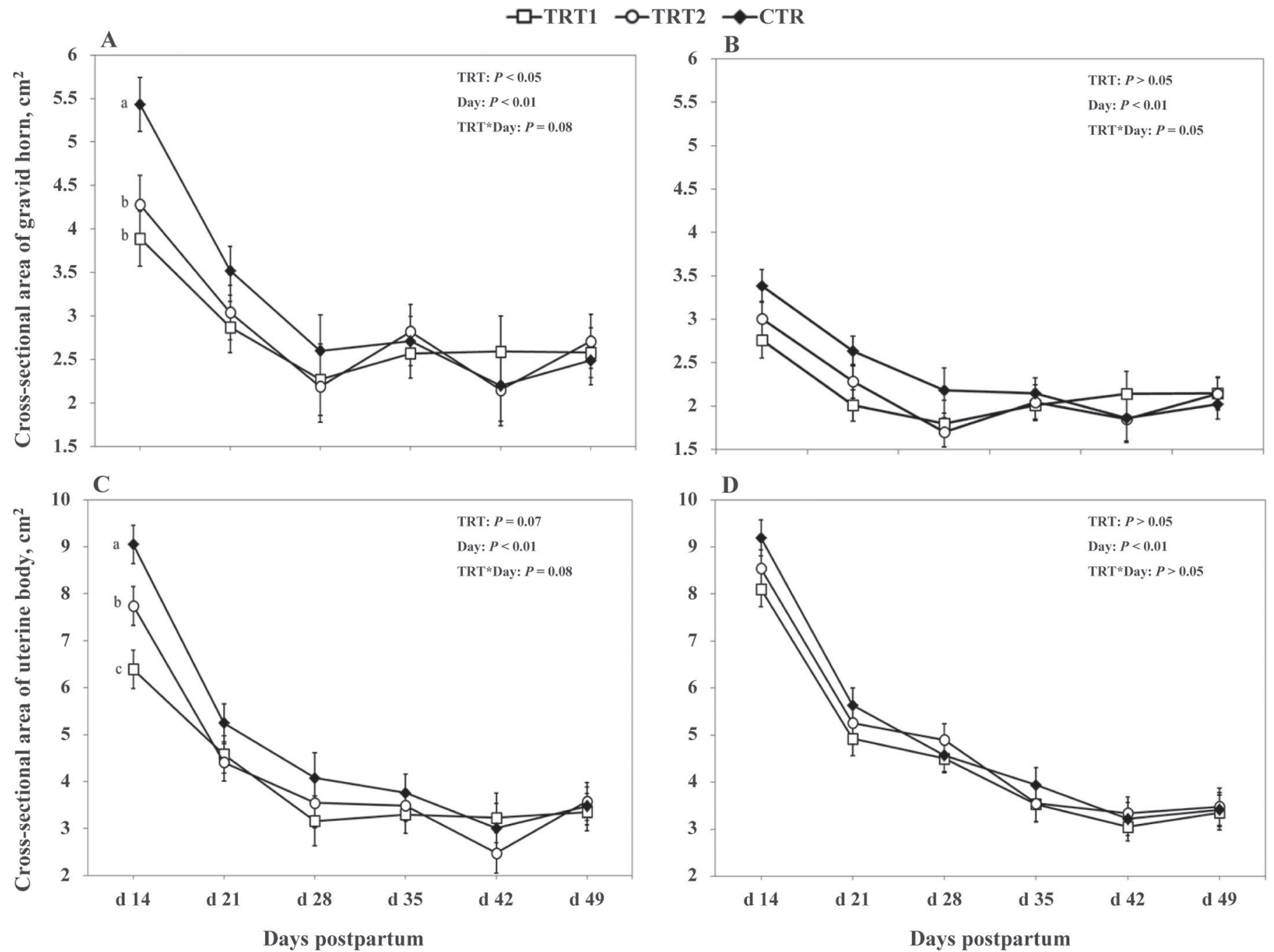

Figure 1. Effect of treatment on the uterine involution of postpartum dairy cows (LSM \pm SEM): (A) gravid horn; (B) nongravid horn; (C) uterine body; (D) cervix. TRT $=$ effect of lactic acid bacteria $(\mathrm{LAB})$ treatment; Day $=$ effect of days relative to calving; TRT $\times$ Day $=$ effect of the interaction between treatment and day. TRT $1=2$ prepartum doses of LAB $(\mathrm{n}=34)$; TRT2 $=2$ prepartum doses plus 1 postpartum dose of LAB $(\mathrm{n}=32)$; CTR $=$ carrier only $(\mathrm{n}=32)$. Different letters $(\mathrm{a}-\mathrm{c})$ indicate a significant difference at a specific time point.

differed among the treatment groups $(P<0.01)$ and increased over time $(P<0.01)$ after calving (Figure $2)$. There were fewer cyclic cows in TRT1 compared with TRT2 and CTR $(P<0.01)$, whereas no difference was observed between TRT2 and CTR cows. By d 49 postpartum, $47.06 \%$ of the cows in TRT1 had resumed ovarian cyclicity compared with $72.41 \%$ in TRT2 and $65.71 \%$ in the CTR cows. Parity had no effect regarding the resumption of ovarian cyclicity of the cows. Moreover, data showed no differences in follicular cyst incidence rate in treatment groups, with TRT1, TRT2, and CTR having 8.8, 6.9, and $14.3 \%$ of cows with cysts within $49 \mathrm{~d}$ after calving.

\section{Effect of Intravaginal $L A B$ on Reproductive Performance}

We detected differences among treatment groups in the mean number of days open $(P<0.05$; Table 2$)$. Cows in TRT1 had 40 fewer days open than their counterparts in TRT2 (110 vs. $150 \mathrm{~d}, P<0.05)$ and CTR (110 vs. $150, P<0.05)$. No differences in days open were observed between TRT2 and CTR. The KaplanMeier survival curve is shown in Figure 3. Treatment had no effect on first-service conception rate, cumulative pregnancy rate, pregnancy rate at 150 DIM, or services per conception. 


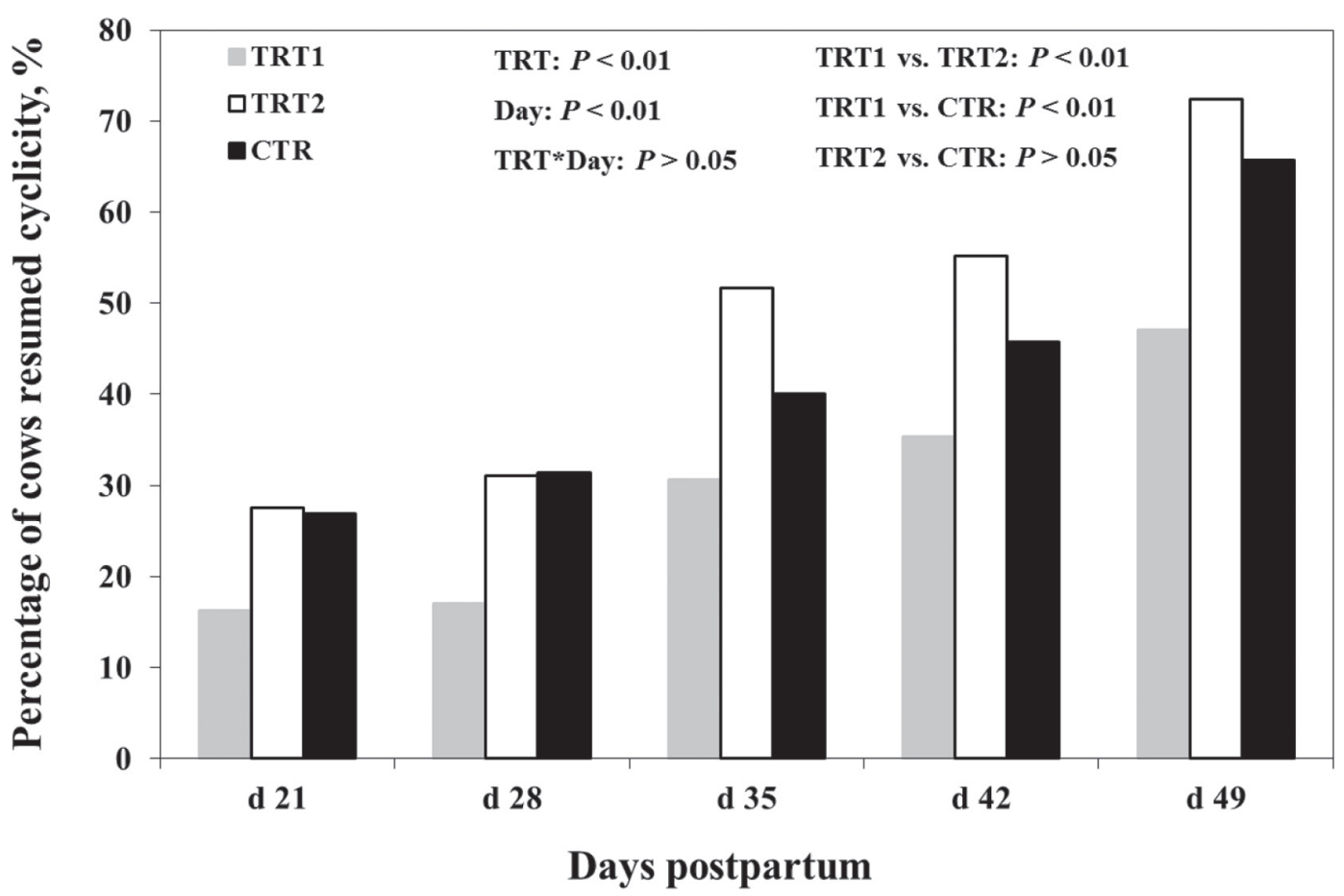

Figure 2. Effect of treatment on the resumption of ovarian cyclicity after parturition. TRT = effect of lactic acid bacteria (LAB) treatment; Day $=$ effect of days relative to calving; TRT $\times$ Day $=$ effect of the interaction between treatment and day. TRT $1=2$ prepartum doses of LAB $(\mathrm{n}=34) ;$ TRT2 $=2$ prepartum doses plus 1 postpartum dose of LAB $(\mathrm{n}=32) ; \mathrm{CTR}=$ carrier only $(\mathrm{n}=32)$.

\section{Effect of Intravaginal LAB on Reproduction- Related Hormones}

A significant interaction was found between treatment and day with regards to concentrations of serum PGFM $(P<0.05$; Figure 4A). We found no differences in serum PGFM at $\mathrm{d}-14$ and $\mathrm{d}-7$ among treatment groups, and all concentrations were at a low basal level. However, concentrations of serum PGFM increased sharply within the last $7 \mathrm{~d}$ before parturition, peaked immediately after parturition (d 0), and decreased rapidly to the prepartum level by d 14 postpartum $(P<$

Table 2. Effect of treatment on reproductive performance of dairy cows

\begin{tabular}{lcccc}
\hline & \multicolumn{3}{c}{ Treatment $^{1}$} \\
\cline { 2 - 3 } Variable & TRT1 & TRT2 & CTR & P-value \\
\hline First-service conception rate, \% (no./no.) & $44.1(15 / 34)$ & $25.0(8 / 32)$ & $40.6(13 / 32)$ & 0.33 \\
Cumulative pregnancy rate, \% (no./no.) & $76.5(26 / 34)$ & $71.9(23 / 32)$ & $78.1(25 / 32)$ & 0.99 \\
Pregnancy rate at 150 DIM, \% (no./no.) & $70.6(24 / 34)$ & $62.5(20 / 32)$ & $75.0(24 / 32)$ & 0.91 \\
Services per conception & $2.4 \pm 0.3$ & $2.7 \pm 0.2$ & $2.3 \pm 0.2$ & 0.29 \\
Mean ( \pm SD) & 2.0 & 3.0 & 2.0 & \\
Median & 1.0 & 1.5 & 1.0 & \\
25th percentile & 5.0 & & & \\
75th percentile & $110 \pm 8^{\mathrm{b}}$ & $150 \pm 11^{\mathrm{a}}$ & $150 \pm 13^{\mathrm{a}}$ & \\
Days open, d & 100 & 146 & 138 & \\
Mean ( \pm SD) & 70 & 104 & 72 & \\
Median & 170 & 215 & 215 & \\
25th percentile & & & \\
75th percentile & & & \\
\hline
\end{tabular}

${ }_{\mathrm{a}, \mathrm{b}}$ Values within a row with different superscript letters are different at $P<0.05$.

${ }^{1} \mathrm{TRT} 1=2$ prepartum doses of lactic acid bacteria $(\mathrm{LAB} ; \mathrm{n}=34)$; TRT2 $=2$ prepartum doses plus 1 postpartum dose of LAB $(\mathrm{n}=32)$; CTR $=$ carrier only $(\mathrm{n}=32)$.

${ }^{2}$ Cumulative pregnancy rate: up to $5 \mathrm{AI}$. 


\section{Product-Limit Survival Estimates}

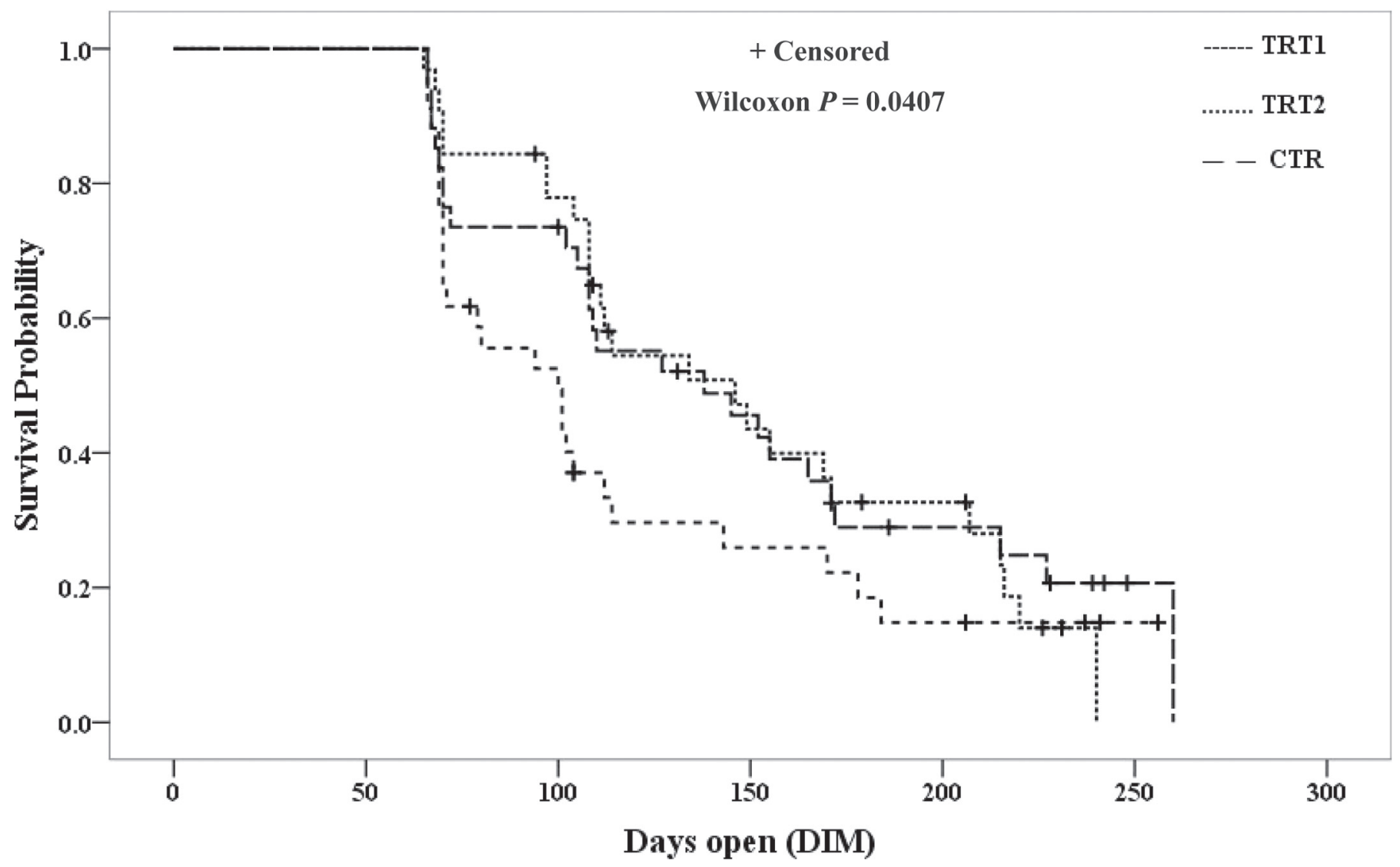

Figure 3. Product-limit (Kaplan-Meier) survival curve of days open for dairy cows in the treatment groups. TRT1 $=2$ prepartum doses of lactic acid bacteria $(\mathrm{LAB} ; \mathrm{n}=34)$; TRT2 $=2$ prepartum doses plus 1 postpartum dose of $\mathrm{LAB}(\mathrm{n}=32)$; CTR $=$ carrier only $(\mathrm{n}=32)$.

0.01). After parturition (d 0), concentrations of serum PGFM in both TRT1 and TRT2 were greater than in CTR $(3,533 \pm 328 \mathrm{pg} / \mathrm{mL}$ in TRT1, $4,470 \pm 372 \mathrm{pg} / \mathrm{mL}$ in TRT2, and 2,000 $\pm 328 \mathrm{pg} / \mathrm{mL}$ in CTR, respectively; $P<0.01)$ and that in TRT2 tended to be greater than that in TRT1 $(P=0.06)$.

Concentrations of serum $\mathrm{PGE}_{2}$ differed among the 3 treatment groups $(P<0.01 ;$ Figure $4 \mathrm{~B})$. Cows in TRT2 had greater concentrations of serum $\mathrm{PGE}_{2}$ than those in the CTR group $(P<0.05)$ and in TRT1 $(P<0.01)$. No differences were found in $\mathrm{PGE}_{2}$ levels between TRT1 and CTR cows. Overall, concentrations of serum $\mathrm{PGE}_{2}$ varied over time $(P<0.01)$, decreasing at parturition, and then increasing on $\mathrm{d} 14$ and 21 postpartum. The effects of treatment and day were independent from each other, as their interaction did not reach significance.

The ratio of PGFM:PGE $\mathrm{P}_{2}$ differed among treatment groups $(P<0.05$; Figure 4C). Both TRT1 (17.18) and TRT2 (17.45) had a greater ratio of PGFM:PGE 2 than the CTR cows (8.59) on d 0. In all cows, the ratio of PGFM:PGE ${ }_{2}$ increased sharply from $\mathrm{d}-7$, peaked on $\mathrm{d}$
0 , and then gradually decreased to the prepartum level by d $14(P<0.01)$. No interaction between treatment and day was observed for the ratio of PGFM:PGE ${ }_{2}$.

Concentrations of serum progesterone differed among treatment groups $(P<0.01)$ and varied over time $(P$ $<0.01$; Figure 5 ). Cows in TRT2 had greater concentrations of progesterone than did those in TRT1 and CTR on d 35 and 49 . We found no difference between cows in the TRT1 and CTR groups. We observed a sharp decrease in progesterone concentrations from $>7$ $\mathrm{ng} / \mathrm{mL}$ on $\mathrm{d}-14$ to $<1 \mathrm{ng} / \mathrm{mL}$ at calving, and then concentrations remained at basal level until $21 \mathrm{~d}$ after calving, when an increase occurred. No differences were detected regarding the interaction between treatment and days related to calving.

\section{DISCUSSION}

In this study, we tested the hypothesis that 2 or 3 intravaginal infusions of LAB around calving would expedite uterine involution and improve reproductive 

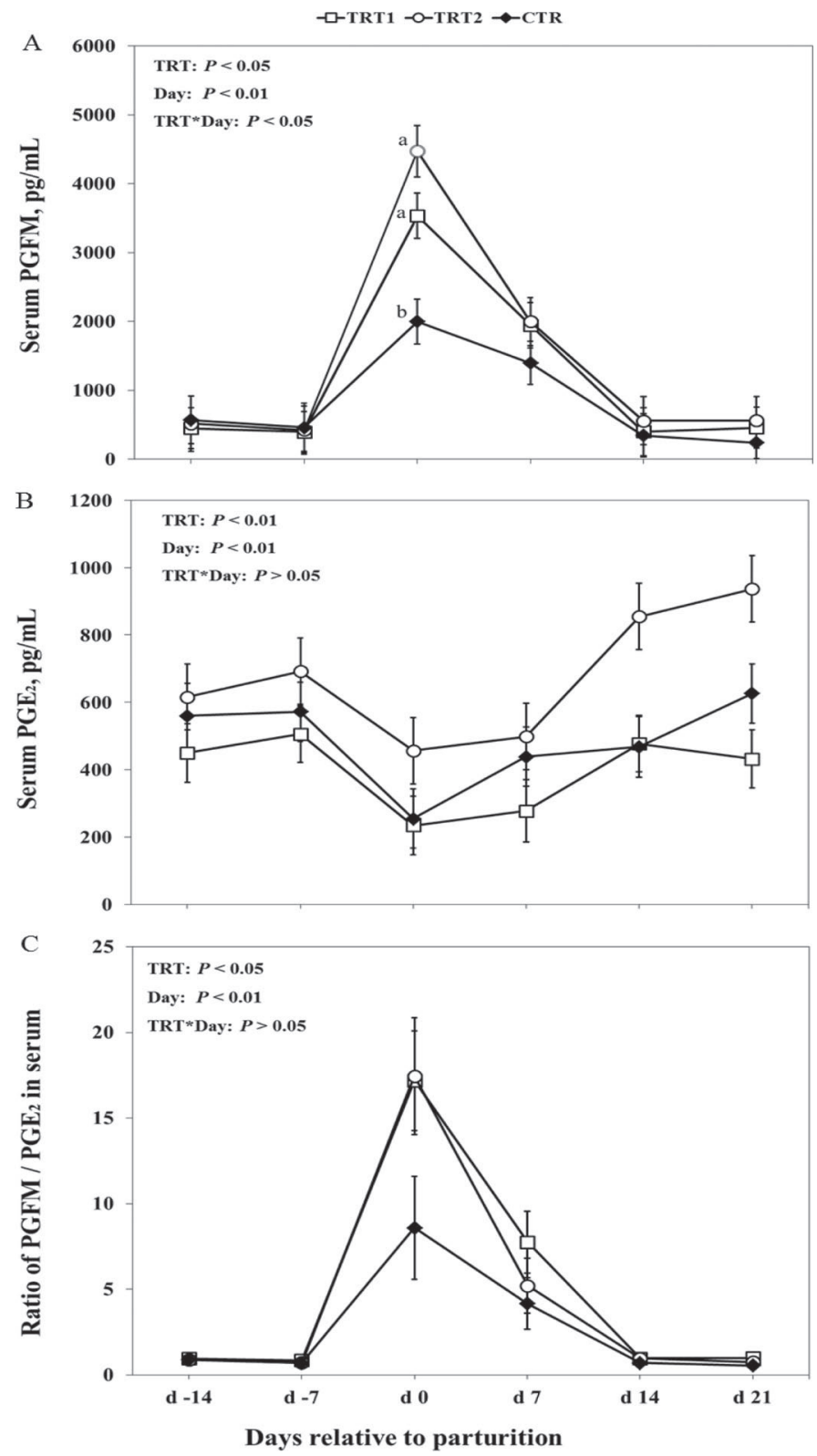

Figure 4. Effect of treatment on serum prostaglandins (LSM \pm SEM): (A) 13,14-dihydro-15-keto- $\mathrm{PFG}_{2 \alpha}$ (PGFM); (B) $\mathrm{PGE}_{2}$; (C)

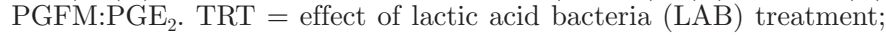
Day $=$ effect of days relative to calving; TRT $\times$ Day $=$ effect of the interaction between treatment and day. TRT $1=2$ prepartum doses of LAB $(\mathrm{n}=10)$; TRT $2=2$ prepartum doses plus 1 postpartum dose of LAB $(\mathrm{n}=10)$; CTR $=$ carrier only $(\mathrm{n}=10)$. Different letters $(\mathrm{a}, \mathrm{b})$ indicate a significant difference at a specific time point.

performance of dairy cows. The probiotic culture used in this study was a mixture of $3 \mathrm{LAB}$ strains isolated previously from the vaginal tract of healthy pregnant cows (Wang et al., 2013; Ametaj et al., 2014). Uterine infections were also monitored but showed no interaction with LAB treatment, which means the effect of $\mathrm{LAB}$ treatment on the targeted variables is indepen-

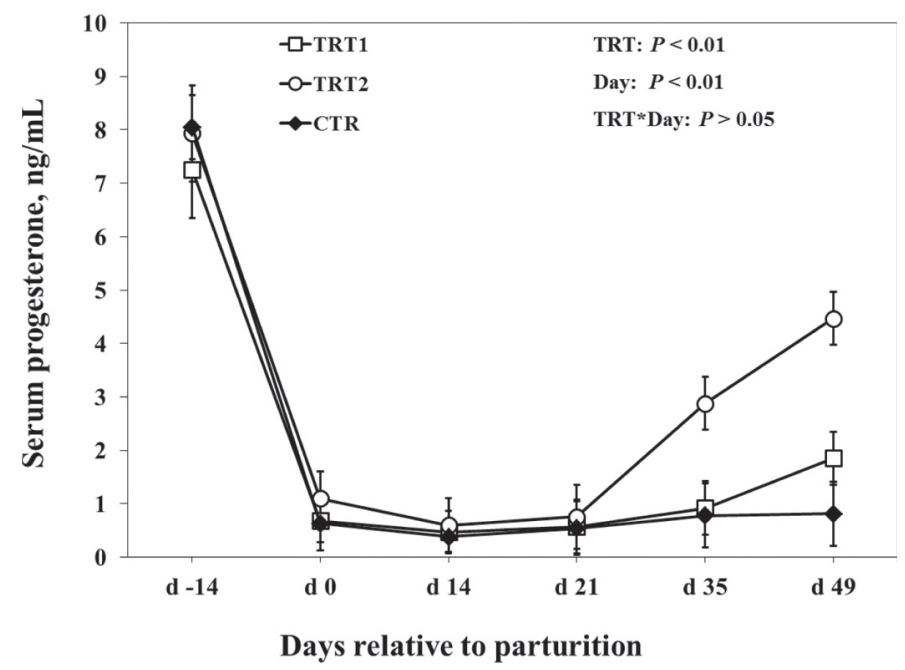

Figure 5. Effect of treatment on the concentration of serum progesterone $(\mathrm{LSM} \pm \mathrm{SEM}) . \mathrm{TRT}=$ effect of lactic acid bacteria $(\mathrm{LAB})$ treatment; Day $=$ effect of days relative to calving; TRT $\times$ Day $=$ effect of the interaction between treatment and day. TRT1 $=2$ prepartum doses of LAB $(\mathrm{n}=10)$; TRT2 $=2$ prepartum doses plus 1 postpartum dose of LAB $(\mathrm{n}=10)$; CTR $=$ carrier only $(\mathrm{n}=10)$.

dent from uterine infections. Indeed, data from this study showed that intravaginal administration of 2 or 3 $\mathrm{LAB}$ doses expedited uterine involution of postpartum dairy cows, as indicated by smaller CSA of gravid horn and uterine body on d 14 in cows treated with LAB (both TRT1 and TRT2).

Normally, the postpartum uterus is assumed to complete involution between 4 and 6 wk postpartum (Sheldon, 2004). Results of this study showed that the involution process of the gravid horn was completed within the first $21 \mathrm{~d}$ after parturition for the LAB-treated groups of cows. This is supported by the observation that there were no significant changes in the CSA of the gravid horn after $21 \mathrm{~d}$ postpartum in LAB-treated cows. Meanwhile, CTR cows completed their uterine involution within $28 \mathrm{~d}$ from parturition day.

Several factors have been identified as affecting the uterine involution rate in postpartum cows, such as breed, parity, environment, calving season, milk yield, and diet (Fonseca et al., 1983; Eduvie, 1985; Zain et al., 1995). However, given that all cows in this study were of the same breed, shared the same environmental and management conditions, and were fed the same diet during each period, those factors can be excluded from our discussion. In addition, milk yield from previous year, feed intake, and BCS did not differ among the 3 groups of cows in this study (data not presented). Parity affected the involution rate of gravid and nongravid horns as well as on uterine body, which has been partitioned from the total effect. Therefore, our search regarding the potential mechanisms underlying the 
smaller gravid horn and uterine body on d 14 focused on the health condition of the reproductive tract.

Kindahl et al. (1999) suggested a relationship between uterine health status and $\mathrm{PGF}_{2 \alpha}$ levels by indicating that pulsatile elevations of $\mathrm{PGF}_{2 \alpha}$ are negatively correlated with involution time in normal cows and positively correlated in cows with endometritis and retained placenta. Prostaglandin $\mathrm{F}_{2 \alpha}$ plays an important role in expediting postpartum uterine involution as well as clearing the fetal remnants and birth canal-ascended bacteria in the reproductive tract due to its efficacy in stimulating myometrial contractions. Consequently, we looked at the concentration of $\mathrm{PGF}_{2 \alpha}$ in the serum as indicated by the concentration of its metabolite PGFM (Seals et al., 2002; Lewis, 2003). Cows in both TRT1 and TRT2 had greater concentrations of PGFM relative to CTR cows immediately after parturition (d 0), which supported our speculation that the smaller gravid horn and uterine body on d 14 was probably related to increased secretion of $\mathrm{PGF}_{2 \alpha}$. These data are in agreement with those of Lindell et al. (1982), who reported that cows with longer duration of the postpartum $\mathrm{PGF}_{2 \alpha}$ release had relatively shorter involution times. Seals et al. (2002) also showed that low concentrations of PGFM during the first $14 \mathrm{~d}$ postpartum seem to be an indicator of cows susceptible to uterine infections during the third week or so postpartum.

Another important prostaglandin involved in uterine health and reproductive performance is $\mathrm{PGE}_{2}$. Cows in TRT2 exhibited elevated serum $\mathrm{PGE}_{2}$, which was not observed in cows in TRT1. Prostaglandin $\mathrm{E}_{2}$ has been demonstrated to induce production of progesterone from luteal cells of the ovaries and, vice versa, progesterone was found to stimulate $\mathrm{PGE}_{2}$ production by the same cells in vitro (Kotwica et al., 2003). That might account for the greater concentration of progesterone in TRT2 than both TRT1 and CTR cows.

In cattle, $\mathrm{PGF}_{2 \alpha}$ is luteolytic to mature corpora lutea, it triggers uterine contractions, and has proinflammatory activity, whereas $\mathrm{PGE}_{2}$ is luteotropic and myorelaxant and has anti-inflammatory activity (Slama et al., 1991; Lewis, 2003). Several reports indicate that uterine infections caused by pathogenic bacteria such as Escherichia coli switch prostaglandin profiles from PGFM to $\mathrm{PGE}_{2}$, lowering the PGFM:PGE ${ }_{2}$ ratio (Herath et al., 2009; Sheldon et al., 2009b). In this study, treatment with LAB increased the ratio of PGFM:PGE ${ }_{2}$ by eliciting a different prostaglandin profile compared with the pathogenic bacteria.

There were more cows in TRT2 showing earlier ovarian cyclicity compared with cows in TRT1, but not compared with CTR group cows. This result is supported by the greater concentrations of progesterone in the blood of cows in TRT2 than those in TRT1 and the CTR group. Several investigators have reported that the number of cows that do not resume estrous cycle by $60-\mathrm{d}$ postpartum ranges between 6 and $59 \%$ in high-producing dairy herds (Cerri et al., 2004; Santos et al., 2009). Those cows have lower odds of becoming pregnant and greater pregnancy losses after the first insemination (Stevenson et al., 2006).

One of the most important findings of this study was that TRT1 decreased the number of days from calving to conception (i.e., days open) by $40 \mathrm{~d}$ (110 vs. 150 d) compared with CTR; however, TRT2 did not give such benefit to the treated cows. The reason for this difference in days open between the 2 treatment groups is not clear and deserves further investigation. Greater days open is associated with reduced profitability in dairy herds. Numerous studies have documented that additional days in which cows are not pregnant beyond the optimal time postcalving are costly to the dairy farm (Groenendaal et al., 2004; Meadows et al., 2005). In this study, cows in the CTR group exhibited a first-service conception rate of $38.2 \%$, which is in agreement with a previous report indicating that the overall conception rate to first insemination of dairy herds in Alberta is 38.4\% (Ambrose and Colazo, 2007). Of note, no significant effects on first-service conception rate were observed among the treatments in the current study.

Earlier resumption of ovarian cyclicity in postpartum cows is considered important and desirable for improved reproduction, as a shorter interval between calving and first ovulation has been found favorable to the fertility of cows (Kawashima et al., 2006; Galvão et al., 2010; Gautam et al., 2010). However, the earlier resumption of ovarian cyclicity and greater serum progesterone in TRT2 did not translate into better reproductive performance in this study. On the other hand, the TRT1 group, which had fewer cows in earlier cyclicity, resulted in shorter days open, which casts doubt on the notion that earlier cyclicity leads to better fertility. This assumption is supported by reports from other researchers, such as Smith and Wallace (1998), who showed that cyclicity before 21 DIM resulted in lower pregnancy rates and greater days open. Moreover, some authors have indicated that neither naturally delayed timing to first estrus nor suppressed first ovulation influence final fertility (Sakaguchi et al., 2004; Heppelmann et al., 2013). Additionally, the same authors reported that delayed cyclicity accelerated uterine involution of postpartum dairy cows (Sakaguchi et al., 2004; Heppelmann et al., 2013), which agrees with our observation that TRT1 had fewer cows resuming cyclicity but smaller uterine body size on d 14 compared with TRT2. This phenomenon is believed to be associated with greater concentrations of progesterone and 
possibly $\mathrm{PGE}_{2}$, which is known for its relaxing effect on myometrium contractions and immunosuppressive effect on uterine defenses that delays uterine involution (Sakaguchi et al., 2004; Heppelmann et al., 2013). Therefore, it is speculated that in the first $49 \mathrm{~d}$ after calving, $\mathrm{PGF}_{2 \alpha}$-driven uterine involution is more crucial for the subsequent fertility. With regards to the different outcomes of the $2 \mathrm{LAB}$ treatments, it should be noted that although TRT2 had 3 doses of LAB compared with the 2 doses used in TRT1, the final dose in TRT2 was administered after calving, when the uterus is contaminated by pathogenic bacteria and under a different microbial environment compared with that precalving. It would be interesting to investigate the mechanisms causing the discrepancy between prepartum and early postpartum administrations of LAB.

\section{CONCLUSIONS}

Taken together, the results of this study indicated that LAB-treated groups had smaller CSA of the gravid horn and uterine body on d 14 and increased concentrations of PGFM in the serum immediately after parturition. Administration of LAB before calving (TRT1) decreased the number of days open in treated cows. However, administration of LAB around calving (TRT2) was associated with greater concentrations of $\mathrm{PGE}_{2}$ and progesterone in the serum postpartum. Differences between the $2 \mathrm{LAB}$ treatments might be related to alterations in the vaginal microbiota composition induced by the 2 treatments in the vaginal tract of supplemented cows. Overall, intravaginal administration of LAB could be used to expedite uterine involution and modify serum concentrations of prostaglandins in transition dairy cows. However, more research is warranted to better understand the mechanism(s) by which intravaginal LAB around calving differ in terms of the effects on ovarian cyclicity and reproductive performance in transition dairy cows.

\section{ACKNOWLEDGMENTS}

We acknowledge the financial support of the funding agencies: Alberta Livestock and Meat Agency Ltd. (ALMA, Edmonton, AB, Canada), Alberta Milk (Edmonton, AB, Canada), and Natural Sciences and Engineering Research Council of Canada (NSERC, Ottawa, ON, Canada) for this project. We also acknowledge the contribution of Yvonne Wang (University of Alberta, Edmonton, AB, Canada) for preparation of LAB cocktail. We are grateful to the technical staff of the Dairy Research and Technology Centre, University of Alberta, for their help with and care of the cows.

\section{REFERENCES}

Ambrose, D. J., and M. G. Colazo. 2007. Reproductive status of dairy herds in Alberta: A closer look. Adv. Dairy Technol. 19:227-244.

Ambrose, D. J., J. P. Kastelic, R. Corbett, P. A. Pitney, H. V. Petit, J. A. Small, and P. Zalkovic. 2006. Lower pregnancy losses in lactating dairy cows fed a diet enriched in alpha-linolenic acid. J. Dairy Sci. 89:3066-3074.

Ametaj, B. N., S. Iqbal, F. Selami, J. F. Odhiambo, Y. Wang, M. G. Gänzle, S. M. Dunn, and Q. Zebeli. 2014. Intravaginal administration of lactic acid bacteria modulated the incidence of purulent vaginal discharges, plasma haptoglobin concentrations, and milk production in dairy cows. Res. Vet. Sci. 96:365-370.

Barrons, R., and D. Tassone. 2008. Use of Lactobacillus probiotics for bacterial genitourinary infections in women: A review. Clin. Ther. 30:453-468.

Bekana, M., P. Jonsson, and H. Kindahl. 1996. Intrauterine bacterial findings and hormonal profiles in post-partum cows with normal puerperium. Acta Vet. Scand. 37:251-263.

Bondurant, R. H. 1999. Inflammation in the bovine female reproductive tract. J. Anim. Sci. 77:101-110.

Borchers, A. T., C. Selmi, F. J. Meyers, C. L. Keen, and M. E. Gershwin. 2009. Probiotics and immunity. J. Gastroenterol. 44:26-46.

CanWest DHI. 2013. Culling and replacement rates of dairy herds in Canada. Accessed Jun. 23, 2014. http://www.dairyinfo.gc.ca/pdf/ genetics-cull_e.pdf.

Cerri, R. L. A., J. E. P. Santos, S. O. Juchem, K. N. Galvão, and R. C. Chebel. 2004. Timed artificial insemination with estradiol cypionate or insemination at estrus in high-producing dairy cows. J. Dairy Sci. 87:3704-3715.

Eduvie, L. O. 1985. Factors affecting postpartum ovarian activity and uterine involution in Zebu cattle indigenous to Nigeria. Anim. Reprod. Sci. 8:123-128.

Fonseca, F. A., J. H. Britt, B. T. McDaniel, J. C. Wilk, and A. H. Rakes. 1983. Reproductive traits of Holsteins and Jerseys. Effects of age, milk yield, and clinical abnormalities on involution of cervix and uterus, ovulation, estrous cycles, detection of estrus, conception rate, and days open. J. Dairy Sci. 66:1128-1147.

Galvão, K. N. 2011. Identifying and treating uterine disease in dairy cows. Pages 21-29 in Proc. 47th Florida Dairy Production Conference, Gainesville, FL. University of Florida, Gainesville.

Galvão, K. N., M. Frajblat, W. R. Butler, S. B. Brittin, C. L. Guard, and R. O. Gilbert. 2010. Effect of early postpartum ovulation on fertility in dairy cows. Reprod. Domest. Anim. 45:e207-e211.

Gautam, G., T. Nakao, K. Yamada, and C. Yoshida. 2010. Defining delayed resumption of ovarian activity postpartum and its impact on subsequent reproductive performance in Holstein cows. Theriogenology 73:180-189.

Groenendaal, H., D. T. Galligan, and H. A. Mulder. 2004. An economic spreadsheet model to determine optimal breeding and replacement decisions for dairy cattle. J. Dairy Sci. 87:2146-2157.

Heppelmann, M., A. Brömmling, M. Weinert, M. Piechotta, C. Wrenzycki, and H. Bollwein. 2013. Effect of postpartum suppression of ovulation on uterine involution in dairy cows. Theriogenology 80:519-525.

Herath, S., S. T. Lilly, D. P. Fischer, E. J. Williams, H. Dobson, C. E. Bryant, and I. M. Sheldon. 2009. Bacterial lipopolysaccharide induces an endocrine switch from prostaglandin $\mathrm{F}_{2 \alpha}$ to prostaglandin $\mathrm{E}_{2}$ in bovine endometrium. Endocrinology 150:1912-1920.

Homayouni, A., P. Bastani, S. Ziyadi, S. Mohammad-AlizadehCharandabi, M. Ghalibaf, A. M. Mortazavian, and E. V. Mehrabany. 2014. Effects of probiotics on the recurrence of bacterial vaginosis: A review. J. Low. Genit. Tract Dis. 18:79-86.

Huszenicza, G., M. Fodor, M. Gacs, M. Kulcsar, M. J. W. Dohmen, M. Vamos, L. Porkolab, T. Kegl, J. Bartyik, J. A. C. M. Lohuis, S. Janosi, and G. Szita. 1999. Uterine bacteriology, resumption of cyclic ovarian activity and fertility in postpartum cows kept in large-scale dairy herds. Reprod. Domest. Anim. 34:237-245.

Kasimanickam, R., T. F. Duffield, R. A. Foster, C. J. Gartley, K. E. Leslie, J. S. Walton, and W. H. Johnson. 2004. Endometrial cytol- 
ogy and ultrasonography for the detection of subclinical endometritis in postpartum dairy cows. Theriogenology 62:9-23.

Kawashima, C., E. Kaneko, C. Amaya Montoya, M. Matsui, N. Yamagishi, N. Matsunaga, M. Ishii, K. Kida, Y. Miyake, and A. Miyamoto. 2006. Relationship between the first ovulation within three weeks postpartum and subsequent ovarian cycles and fertility in high producing dairy cows. J. Reprod. Dev. 52:479-486.

Kindahl, H., M. Bekana, K. Kask, K. Königsson, H. Gustafsson, and K. Odensvik. 1999. Endocrine aspects of uterine involution in the cow. Reprod. Domest. Anim. 34:261-268.

Kotwica, J., D. Skarzynski, J. Mlynarczuk, and R. Rekawiecki. 2003 Role of prostaglandin $\mathrm{E}_{2}$ in basal and noradrenaline-induced progesterone secretion by the bovine corpus luteum. Prostaglandins Other Lipid Mediat. 70:351-359.

Lewis, G. S. 1997. Uterine health and disorders. J. Dairy Sci. 80:984994.

Lewis, G. S. 2003. Steroidal regulation of uterine resistance to bacterial infection in livestock. Reprod. Biol. Endocrinol. 1:117-125.

Lindell, J.-O., H. Kindahl, L. Jansson, and L.-E. Edqvist. 1982. Postpartum release of prostaglandin $\mathrm{F}_{2}$ and uterine involution in the cow. Theriogenology 17:237-245.

Mateus, L., L. L. da Costa, F. Bernardo, and J. R. Silva. 2002. Influence of puerperal uterine infection on uterine involution and postpartum ovarian activity in dairy cows. Reprod. Domest. Anim. 37:31-35.

Meadows, C., P. J. Rajala-Schultz, and G. S. Frazer. 2005. A spreadsheet-based model demonstrating the nonuniform economic effects of varying reproductive performance in Ohio dairy herds. J. Dairy Sci. 88:1244-1254.

Melendez, P., J. McHale, J. Bartolome, L. F. Archbald, and G. A Donovan. 2004. Uterine involution and fertility of Holstein cows subsequent to early postpartum $\mathrm{PGF}_{2 \alpha}$ treatment for acute puerperal metritis. J. Dairy Sci. 87:3238-3246.

Okano, A., and T. Tomizuka. 1987. Ultrasonic observation of postpartum uterine involution in the cow. Theriogenology 27:369-376.

Reid, G., and A. W. Bruce. 2003. Urogenital infections in women: Can probiotics help? Postgrad. Med. J. 79:428-432.

Reid, G., J. Jass, M. T. Sebulsky, and J. K. McCormick. 2003. Potential uses of probiotics in clinical practice. Clin. Microbiol. Rev. 16:658-672.

Sakaguchi, M., Y. Sasamoto, T. Suzuki, Y. Takahashi, and Y. Yamada. 2004. Postpartum ovarian follicular dynamics and estrous activity in lactating dairy cows. J. Dairy Sci. 87:2114-2121.
Santos, J. E., H. M. Rutigliano, and M. F. Sá Filho. 2009. Risk factors for resumption of postpartum estrous cycles and embryonic survival in lactating dairy cows. Anim. Reprod. Sci. 110:207-221.

Seals, R. C., I. Matamoros, and G. S. Lewis. 2002. Relationship between postpartum changes in 13,14 -dihydro-15-keto- $\mathrm{PGF}_{2 \alpha}$ concentrations in Holstein cows and their susceptibility to endometritis. J. Anim. Sci. 80:1068-1073.

Sheldon, I. M. 2004. The postpartum uterus. Vet. Clin. North Am. Food Anim. Pract. 20:569-591.

Sheldon, I. M., J. Cronin, L. Goetze, G. Donofrio, and H. J. Schuberth. 2009a. Defining postpartum uterine disease and the mechanisms of infection and immunity in the female reproductive tract in cattle. Biol. Reprod. 81:1025-1032.

Sheldon, I. M., G. S. Lewis, S. LeBlanc, and R. O. Gilbert. 2006. Defining postpartum uterine disease in cattle. Theriogenology 65:1516-1530.

Sheldon, I. M., S. B. Price, J. Cronin, R. O. Gilbert, and J. E. Gadsby. 2009b. Mechanisms of infertility associated with clinical and subclinical endometritis in high producing dairy cattle. Reprod. Domest. Anim. 44:1-9.

Slama, H., D. Vaillancourt, and A. K. Goff. 1991. Pathophysiology of the puerperal period: Relationship between prostaglandin E2 $\left(\mathrm{PGE}_{2}\right)$ and uterine involution in the cow. Theriogenology 36:1071-1090.

Smith, M. C., and J. M. Wallace. 1998. Influence of early postpartum ovulation on the re-establishment of pregnancy in multiparous and primiparous dairy cattle. Reprod. Fertil. Dev. 10:207-216.

Stevenson, J. S., J. R. Pursley, H. A. Garverick, P. M. Fricke, D. J. Kesler, J. S. Ottobre, and M. C. Wiltbank. 2006. Treatment of cycling and noncycling lactating dairy cows with progesterone during Ovsynch. J. Dairy Sci. 89:2567-2578.

Verdu, E. F., and S. M. Collins. 2005. Irritable bowel syndrome and probiotics: From rationale to clinical use. Curr. Opin. Gastroenterol. 21:697-701.

Wang, Y., B. N. Ametaj, D. J. Ambrose, and M. G. Gänzle. 2013. Characterization of the bacterial microbiota of the vagina of dairy cows and isolation of pediocin producing Pediococcus acidilactici. BMC Microbiol. 13:19-29.

Zain, A. E. D., T. Nakao, M. A. Raouf, M. Moriyoshi, K. Kawata, and Y. Moritsu. 1995. Factors in the resumption of ovarian activity and uterine involution in postpartum dairy cows. Anim. Reprod. Sci. 38:203-214. 